\title{
Comparing breastfeeding experiences between mothers spending the traditional Chinese confinement period in a confinement centre and those staying at home: a cohort study
}

\author{
Siew Cheng Foong ${ }^{*}$ (D), May Loong Tan, Wai Cheng Foong, Jacqueline J. Ho and Fairuz Fadzilah Rahim
}

\begin{abstract}
Background: Ethnic Chinese mothers in Malaysia adhere to 30 days of traditional postpartum practices (the "confinement period") aimed at recuperation after delivery. Recently there has been an emergence of confinement centres (CCs) where mothers stay and receive traditional confinement care. Ethnic Chinese mothers have low breastfeeding rates. There are concerns that practices in CCs could contribute to this but no data exists. We described mothers' breastfeeding experiences at CCs and identified areas for potential improvement in breastfeeding support.

Methods: Ethnic Chinese mothers intending to breastfeed their healthy infants were recruited post-delivery between August and October 2017 then, at 1 and 6 months, they were telephone interviewed about their experience. For every participant going to a CC after the birth, another mother going home ("home") for her confinement was recruited. Chi-square test was used to compare groups and multiple logistic regression was used to assess the effect of confinement place on exclusive breastfeeding.

Results: Of 187 mothers, 88 (47\%) went to CCs. Significantly more were primipara and fewer had previous breastfeeding experience. Response rates for the 1- and 6- month interviews were 88\% (CC) versus 97\% (home); and $77 \%$ (CC) versus $87 \%$ (home) respectively.

Exclusive breastfeeding rates were similar between the groups: $62 \%$ (CC) versus $56 \%$ (home) at 1 month $(p=0.4$ ); and $37 \%$ (CC) versus $42 \%$ (home) at 6 months $(p=0.5$ ). Multiple logistic regression did not show that CCs were a factor affecting exclusive breastfeeding rates at 1 month, (adjusted odds ratio [aOR] 1.7, 95\% confidence interval [Cl] $0.9,3.3$ ), or 6 months (aOR 0.9, 95\% Cl 0.4, 1.7). However, significantly more CC participants only fed expressed breast milk. Despite $66 \%$ of CC participants reporting that their centre supported breastfeeding, only 6 (8\%) CC participants compared to $66(69 \%)$ of home participants roomed-in with their baby $(p<0.001)$. The proportion encountering breastfeeding difficulties were similar between groups. CC participants sought help for breastfeeding (Continued on next page)
\end{abstract}

* Correspondence: scfoong@rcsiucd.edu.my

RCSI \& UCD Malaysia Campus, 4 Jalan Sepoy Lines, George Town, Penang,

Malaysia

C C The Author(s). 2021 Open Access This article is licensed under a Creative Commons Attribution 4.0 International License, which permits use, sharing, adaptation, distribution and reproduction in any medium or format, as long as you give appropriate credit to the original author(s) and the source, provide a link to the Creative Commons licence, and indicate if changes were made. The images or other third party material in this article are included in the article's Creative Commons licence, unless indicated otherwise in a credit line to the material. If material is not included in the article's Creative Commons licence and your intended use is not permitted by statutory regulation or exceeds the permitted use, you will need to obtain permission directly from the copyright holder. To view a copy of this licence, visit http://creativecommons.org/licenses/by/4.0/. The Creative Commons Public Domain Dedication waiver (http://creativecommons.org/publicdomain/zero/1.0/) applies to the data made available in this article, unless otherwise stated in a credit line to the data. 


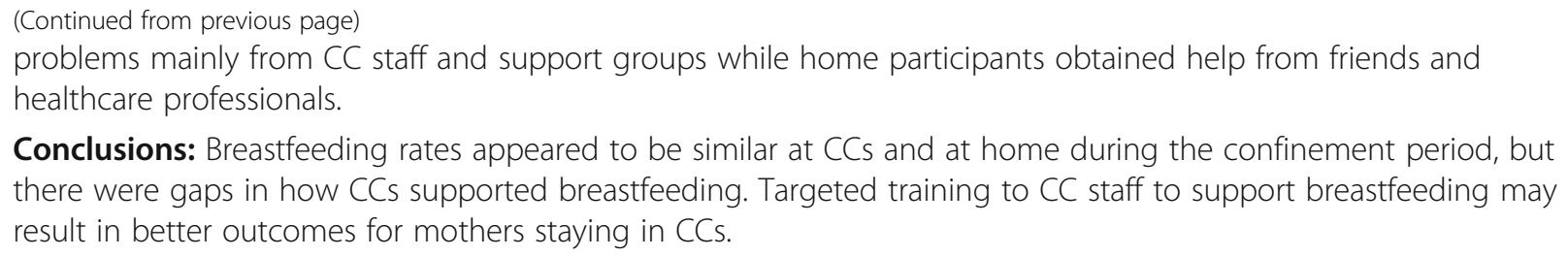

Keywords: confinement centre, postpartum care, breastfeeding, support, barriers, Chinese

\section{Background}

Breastfeeding is the cornerstone of infant nutrition and the dangers of not breastfeeding are well recognised [1]. The early initiation of breastfeeding after birth and subsequent early postpartum establishment of breastfeeding are important for successful breastfeeding [2]. Close and continuous proximity of mother and baby $24 \mathrm{~h}$ a day is also important to the establishment of breastfeeding [3]. In some traditional cultural postpartum practices, restrictions to contact between mother and baby may occur. These may affect mother-infant interaction and breastfeeding practice.

Malaysia has a multi-ethnic society and each ethnic group has its own traditional postnatal practice. Chinese ethnicity is one of the three major groups and despite modernisation, most Chinese women adhere strictly to a 30-day traditional postpartum period, known locally as the "confinement period" or "zuo yue zi" [4-7].

These practices are based on the traditional Chinese belief system about the maintenance of Yin and Yang in the mother after childbirth so that her health is restored. Many believe that non-adherence to these practices will result in potentially long-term adverse effects on the quality of life to the mother. Influences of relatives, in particular the new mother's mother, her mother-in-law and her grandmother, are factors that ensured that these practices are carried out and passed down from generation to generation $[4,7]$.

During the confinement period, the mother would be assisted fully at her home by someone (or sometimes more than one person), ensuring that she gets enough rest, providing the appropriate diet, caring for the newborn baby and ensuring she abides by confinement practices such as keeping warm [5]. This usually means the mother avoids draughts or taking showers for the whole month $[4,7,8]$. This person was traditionally a close female relative [6] but practices have evolved to hiring a "confinement lady" (yue so) who is considered an expert in the necessary diet and practices $[8,9]$. The confinement lady would be employed to stay in the new mother's home after delivery for at least 4 weeks [9].

Over the last decade, a new method of providing this care emerged and is increasingly replacing the role of confinement ladies or female relatives at home.
Confinement centres (CCs) provide a place for postpartum Chinese mothers to stay during their confinement period and observe traditional postpartum practices under the care of the CC staff [9]. A typical CC is often a converted house with several rooms for mothers and a room designed as a nursery where the babies are all placed. Mothers may share rooms and typically all the babies would be in a single 'nursery'. This centre would be staffed by women who have experience with newborns and are familiar with the Chinese cultural confinement requirements, a cook to prepare the required confinement diet for mothers and occasionally qualified nurses to look after the well-being of mothers and babies [9]. Although care of the infant is in no way neglected because the focus of these CCs is mainly towards providing traditional care for the mother, compromises in mother-infant bonding and breastfeeding may occur. This has led to concerns that breastfeeding may not be adequately supported in CCs and further compromising breastfeeding rates for the Chinese population, which is currently the lowest among the major ethnic groups in Malaysia [10,11], despite evidence that a high proportion of them intend to breastfeed [10].

There are currently no published data about breastfeeding practices in confinement centres and this is important because the development of such centres is a growing phenomenon across Asia and beyond. The aim of the study is to describe the breastfeeding experience of ethnic Chinese mothers who stayed in CCs during the traditional confinement period and compare the breastfeeding outcomes at 1 and 6 months with those who stayed at home, to determine if the place of confinement had any effect on breastfeeding, identify current practices and areas for potential improvement in breastfeeding support in confinement centres.

\section{Methods}

This was a prospective cohort study. Participants were recruited from the postnatal wards of six hospitals in Penang, Malaysia between August and October 2017. Malaysian mothers of Chinese ethnicity with the intention to breastfeed their healthy term infants were recruited post-delivery, then telephone interviewed about their experience at 1 and 6 months later. We 
excluded single mothers because they may have different social support which may affect breastfeeding. Recruitment was done by the infant's attending doctor, who apart from this was not otherwise involved in the study. Women who chose to go to a CC were recruited on a consecutive basis and the control selected was as far as possible the next woman from the same hospital who planned home confinement. Participants were told that we wanted to study their breastfeeding experience and the information would be used to improve mothers' experiences in the future. Written consent was obtained from the participants prior to the commencement of study.

After consent was obtained, maternal and infant baseline characteristics were collected before discharge. These included maternal age, educational level, occupation, parity, previous breastfeeding experience, place of intended confinement, infant's date of birth, hospital of birth, gender, gestational age at birth, mode of delivery and birthweight. After discharge, there was no contact between the research team and the participant until after her 30-day confinement period.

A telephone interview with the participant was conducted 1 month postpartum (the end of the confinement period). The focus of this telephone interview was to seek the breastfeeding experiences of participants who stayed at CCs and compare it with those at home. The questions included infant's feeding practices, opportunity to room-in and/or spend time with their infants, problems encountered during breastfeeding (such as engorgement, mastitis, insufficient milk), sources of help for these problems and any perceived barriers to breastfeeding. Participants were given the opportunity to elaborate on any of the questions asked. They were also asked at the end of the interview if there was anything positive or negative about her confinement centre that she would like to share with us. The second telephone interview to collect data on breastfeeding practices was conducted when the infant was 6 months old. All questions used had been tested in a separate group of breastfeeding mothers not involved in the study. Both telephone interviews were conducted by three trained research staff and the responses were directly entered into a specially designed interview form.

\section{Sample size calculation}

Sample size was calculated to be 94 in each group taking into consideration a $20 \%$ drop out rate. This was based on the National Health and Morbidity Survey 2016 exclusive breastfeeding prevalence for Malaysian Chinese mothers at 0 to 2 months of $42.5 \%$ [12] and our hypothesis that there would be a $50 \%$ lower exclusive breastfeeding rate in the $\mathrm{CC}$ group compared to the home group.

\section{Breastfeeding definitions}

We defined exclusive breastfeeding according to the World Health Organisation's definition which means no other food or drink, not even water, except for medicines, vitamins and breast milk (including breastfeeding, milk expressed or from a donor). Any breastfeeding was defined as breast milk (including breastfeeding, milk expressed or milk from a donor), and any other food or liquid including non-human milk and formula [13].

Data on breastfeeding was collected during the 1- and 6- month interview asking the mother how she was mainly feeding her baby.

\section{Data analyses}

We tabulated the baseline demographics of the mothers according to place of confinement. Continuous data was presented as mean with standard deviation (SD) and categorical data presented as frequency with percentage (\%). Chi-square analysis was used to compare the baseline characteristics between participants staying in confinement centres (CCs) and those staying at home. Comments from free field options were tabulated and categorized into groups. Some of these free field responses were quoted as illustrations. Simple logistic regression was used to determine whether CCs affected breastfeeding rates (any breastfeeding and exclusive breastfeeding) at 1 month and 6 months postpartum and presented as crude odds ratio (OR) with $95 \%$ confidence interval (CI). We modeled the likelihood of exclusive breastfeeding or any breastfeeding as a function of CCs using multiple logistic regression by adjusting for other clinically important variables. The results were presented as adjusted odds ratio (aOR) with 95\% CI. Statistical analysis was done using Stata13 [14]. We considered a $p$ value of less than 0.05 as significant.

\section{Results}

A total of 187 mothers consented to participate, of which $88(47 \%)$ chose to stay in a CC. Of the $99(53 \%)$ participants who chose to go home during their confinement period, a third of them employed confinement ladies to provide confinement care at home, while the remainder received their care from family members.

We were able to interview 77 (88\%) participants from the CC group and 96 (97\%) from the home group at 1 month postpartum. At 6 months, 68 (77\%) from the CC group and 86 (87\%) from the home group completed the interview. (See Fig. 1).

\section{Baseline characteristics}

The maternal and infant baseline characteristics are presented in Table 1 . The overall mean maternal age was 32.3 (SD 4.0) years with 54\% having previous experience with breastfeeding and 57\% delivering in a Baby Friendly 


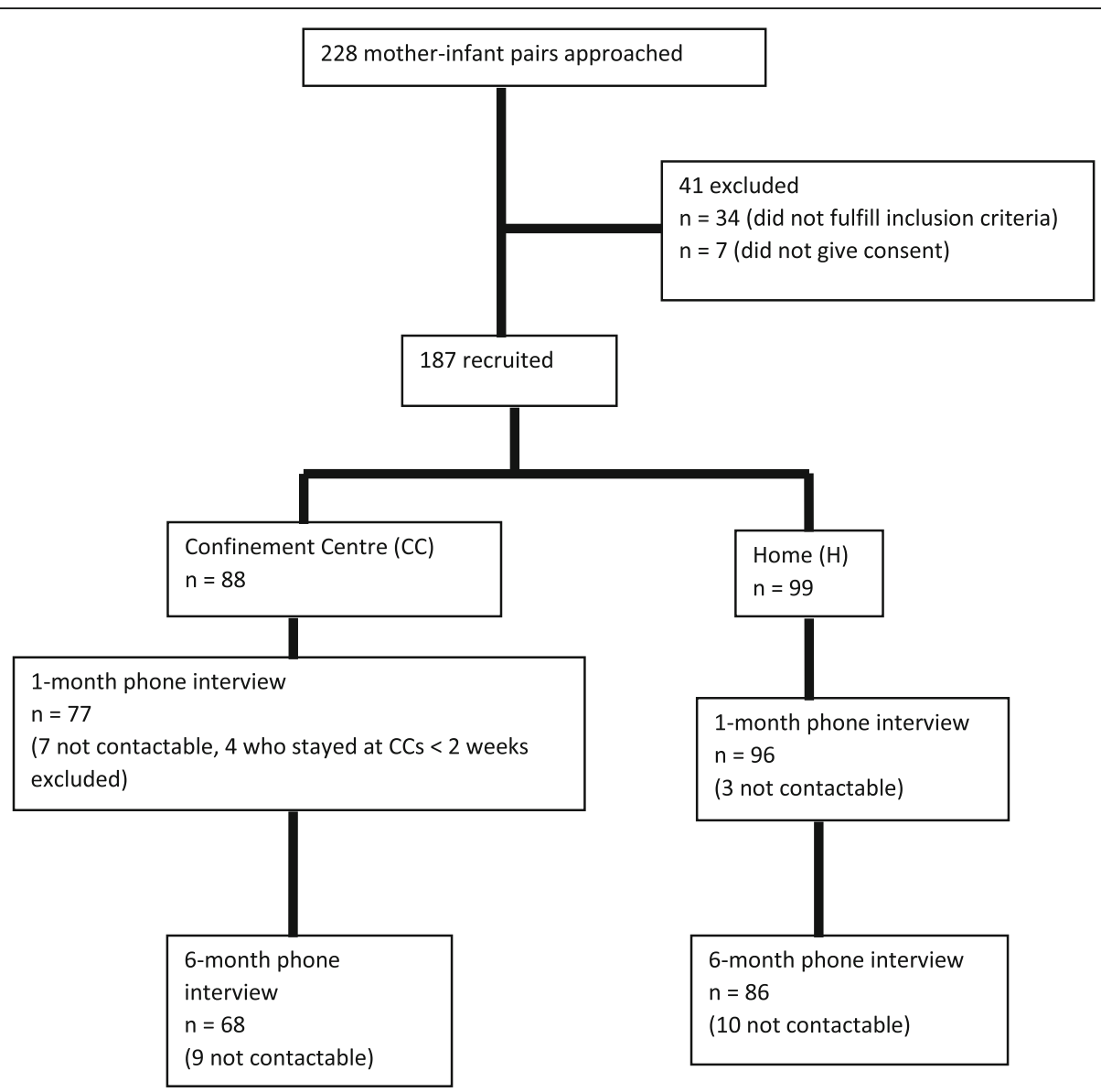

Fig. 1 Study flow diagram

Table 1 Baseline characteristics of the mothers and infants $(N=187)$

\begin{tabular}{|c|c|c|}
\hline \multirow[t]{2}{*}{ Characteristics } & \multicolumn{2}{|c|}{ Place of confinement, $n$ (\%) } \\
\hline & $\begin{array}{l}\text { Confinement centre } \\
(n=88)\end{array}$ & $\begin{array}{l}\text { Home } \\
(n=99)\end{array}$ \\
\hline Age of mothers (years), mean (SD) & $32(4.3)$ & $32(3.3)$ \\
\hline Received tertiary education & $70(79.6)$ & $80(80.8)$ \\
\hline Delivery in BFHI hospital & $49(55.7)$ & $57(57.6)$ \\
\hline Primipara* & $47(53.4)$ & $34(34.3)$ \\
\hline Had previous breastfeeding experience* & $39(44.3)$ & $62(62.6)$ \\
\hline \multicolumn{3}{|l|}{ Mode of delivery } \\
\hline Vaginal & $41(46.6)$ & $51(51.5)$ \\
\hline Instrumental & $15(17.1)$ & $16(16.2)$ \\
\hline Caesarean & $32(36.4)$ & $32(32.3)$ \\
\hline Male infant & $45(51.1)$ & $56(56.6)$ \\
\hline Gestational age at birth (weeks), mean (SD) & $38.72(1)$ & $38.67(1)$ \\
\hline Infant's birthweight (g), mean (SD) & $3141.25(303.6)$ & $3156.07(339.2)$ \\
\hline
\end{tabular}

* $p$ value $<0.05$ 
Hospital Initiative (BFHI) accredited hospital. Most mothers had a tertiary education and all had at least secondary school education, which reflects what is expected in Penang. The overall mean infant gestational age was 38.7 (SD 1) weeks and mean birthweight of 3149 (SD 322) g. There were no differences in the age, education background, delivery at a BFHI accredited hospital, mode of delivery; infant gestation and birthweight between the two groups. However, we found that significantly more primiparas ( $53 \% \mathrm{CC}$ vs $34 \% \mathrm{H}, p=0.01)$ and fewer mothers with prior breastfeeding experience going to CCs $(44 \% \mathrm{CC}$ vs $63 \% \mathrm{H}, p=0.01)$.

\section{Breastfeeding practices at 1 month and 6 months}

At 1 month postpartum, all the interviewed participants were continuing to breastfeed, except two mothers from the home group. There was no difference in the exclusive breastfeeding rates between the two groups $(62 \%$ for $\mathrm{CC}$ and $56 \%$ for home, $p=0.36$ ). Similarly, at 6 months, there was no difference in the exclusive breastfeeding rates between the two groups (37\% for CC and $42 \%$ for home, $p=0.70$ ). Simple logistic regression showed no association between exclusive breastfeeding rates and place of confinement at 1 month, (OR 1.3,95\% CI 0.7, 2.4) or at 6 months, (OR 0.8, 95\% CI 0.4, 1.6). Multiple logistic regression adjusted for known clinically important confounders (education level, past breastfeeding experience, place of delivery, mode of delivery, spent more than $6 \mathrm{~h}$ a day with baby, roomed-in with baby at night, employment status at 6 months) also did not show that the CC or home was a factor affecting exclusive breastfeeding rates at 1 month (aOR 1.7, 95\% CI 0.9, 3.3) and at 6 months (aOR $0.9,95 \%$ CI $0.4,1.7$ ) or 'any breastfeeding rates' at 6 months (aOR 1.1, 95\% CI 0.5, 2.2). We were unable to estimate the odds ratio for 'any breastfeeding rates' at 1 month because all except two participants from the home group were breastfeeding (see Table 2).

Among all participants who were continuing to breastfeed at 1 month $(n=171), 29 \%$ were breastfeeding directly from the breast, $49 \%$ only fed their infants with expressed breast milk (baby was never latched to breast) and $21 \%$ used a combination of both. Significantly more participants from CCs were only feeding expressed breast milk compared to those from home (62\% vs $39 \%$, $p<0.001$ ) at 1 month (See Table 3).

Among participants who only fed expressed breast milk at 1 month $(n=85), 41 \%$ of them stopped breastfeeding by 6 months compared with 35\% of those who had included direct latching to their breastfeeding routine $(p=0.64)$. We explored reasons for not directly breastfeeding at 1 month. The main reason was the perception that direct breastfeeding was very time consuming and prevented them from resting properly $(n=28)$. Other reasons included having problems associated with latching $(n=22)$, the need to monitor baby's milk intake $(n=14)$, and difficulty accessing their baby in the nursery or being discouraged from directly latching their infants $(n=8)$. One mother did not want to place the baby near her breasts saying "I feel dirty because I haven't had a shower for so long."

\section{Breastfeeding experience}

Overall, 66\% of the participants in the CC group reported that their centre was supportive of breastfeeding. When asked reasons for saying so, they cited one or more reasons which we categorised into the following: staff helped them overcome breastfeeding problems, mental support from staff, breastfeeding education given by staff (especially for mothers with no prior breastfeeding experience), availability of peer support from other mothers in the same centre. Of note, none of the participants stated that they perceived their centre to be supportive of breastfeeding because they had received encouragement to spend time with their infant or to breastfeed at night.

For both groups, we asked if they faced any hindrance to breastfeeding. Ten participants from the CC group reported that they did encounter one or more forms of hindrance which we categorized into the following: staff were not helpful with breastfeeding problems; staff encouraged formula feeding; mother was asked to pump less breast-milk because there was inadequate

Table 2 Crude and adjusted ORs for breastfeeding at 1 and 6 months defined by place of confinement

\begin{tabular}{|c|c|c|c|c|}
\hline & $\begin{array}{l}\text { Odds Ratio, } \\
\text { OR ( } 95 \% \mathrm{Cl})\end{array}$ & $p$ value & Adjusted Odds Ratio, aOR $(95 \% \mathrm{Cl})^{\mathrm{a}}$ & $p$ value \\
\hline \multicolumn{5}{|l|}{ At 1 month } \\
\hline Exclusive breastfeeding & $1.3(0.7,2.4)$ & 0.42 & $1.7(0.9,3.3)$ & 0.14 \\
\hline Any breastfeeding ${ }^{b}$ & Not estimable & & Not estimable & \\
\hline \multicolumn{5}{|l|}{ At 6 months } \\
\hline Exclusive breastfeeding & $0.8(0.4,1.6)$ & 0.52 & $0.9(0.4,1.7)$ & 0.67 \\
\hline Any breastfeeding & $1.0(0.5,1.9)$ & 0.99 & $1.1(0.5,2.2)$ & 0.82 \\
\hline
\end{tabular}

${ }^{a}$ Adjusted for maternal education level, past breastfeeding experience, place of delivery, mode of delivery, spent more than $6 \mathrm{~h}$ a day with baby, rooming-in at night, employment status at 6 months

${ }^{\mathrm{b}}$ All mothers except 2 from the home group were practicing some form of breastfeeding 
Table 3 Methods of breastfeeding by place of confinement at 1 month

\begin{tabular}{|c|c|c|}
\hline & $\begin{array}{l}\text { Confinement centre }(N=77) \\
n(\%)\end{array}$ & $\begin{array}{l}\text { Home }(N=96) \\
n(\%)\end{array}$ \\
\hline Expressed milk feeding only & $48(62)$ & $37(39)$ \\
\hline Direct latch feeding only & $9(12)$ & $41(43)$ \\
\hline Direct latch and expressed milk feeding & $20(26)$ & $16(17)$ \\
\hline Stopped breastfeeding & 0 & $2(2)$ \\
\hline
\end{tabular}

refrigerator storage space; family members were against breastfeeding; inappropriate information given regarding breastfeeding such as the need to stop breastfeeding for a jaundiced baby or for diarrhea or skin rashes; or misconceptions such as "baby would be hungry without formula", "breast milk will cause indigestion", "breastfeeding was troublesome and would result in a clingy baby". However, not being allowed to breastfeed at night was not cited as a perceived hinderance to breastfeeding. Interestingly, three of the participants who said they had some hindrance to breastfeeding had earlier considered their centres to be supportive of breastfeeding. On the other hand, eight participants from the home group indicated that they had faced breastfeeding hindrance either because their family members or hired confinement lady did not support breastfeeding.

\section{Sleeping arrangements during the confinement period} Despite $66 \%$ of CC participants reporting that their centre supported breastfeeding, only 57\% reported that their CC allowed mothers to share a room with their babies. However, even among the 43 participants whose CCs allowed them to room-in with their babies, 38 participants said they chose not to do so. They would sleep in their own room (sometimes with a few other mothers in the same room) while their babies slept in a nursery. When we compared CC participants with participants at home, only $8 \%$ of $\mathrm{CC}$ participants actually slept with their babies while $69 \%$ of those from home did so $(p<0.001)$.
Only $73 \%$ of CC participants reported that they could access their babies at any time of the day or night, while the remaining $27 \%$ had some restrictions. In particular, 17 participants reported that their CC discouraged or disallowed breastfeeding at night. Other restrictions included designated times to be with or see their baby through a window in the nursery. We illustrated how much access a mother has to her baby if they did not room-in together in Table 4.

\section{Breastfeeding problems encountered and sources of help} Breastfeeding problems were experienced by 62 participants in the $\mathrm{CC}$ group (81\%) and 73 participants in the home group (76\%). Among those with breastfeeding problems, significantly more participants in CCs (79\%) compared with those at home (59\%) encountered latching difficulties, breast engorgement, blocked ducts, mastitis, abscess and sore nipples ( $n=49$ vs $43, p=0.03$ ). However, there was weak evidence that inadequate milk production was more commonly reported in the CC group compared to the home group ( $n=40$ vs $33, p=$ $0.06)$.

The number of participants who perceived that family members were the main source of hindrance to breastfeeding was similar in both groups ( $n=9$ vs $8, p=0.64$ ).

Sources of help for breastfeeding problems were different for participants in CCs and home. Participants in CCs mainly sought help from centre staff $(n=30,39 \%)$ and breastfeeding support groups $(n=15,19 \%)$ while most home participants obtained help either from friends $(n=16,17 \%)$ or healthcare professionals $(n=19$, $20 \%)$. Only 7 (7\%) of participants staying at home

Table 4 Mother's access to baby in the nursery (for participants who did not share a room with their babies, $n=71$ )

\begin{tabular}{ll}
\hline Description & $\boldsymbol{n}(\%)$ \\
\hline Baby could be brought out of the nursery at any time to be with mother. In addition, mothers could see their babies from outside of the & 51 \\
nursery through a window any time of the day or night. & (66)
\end{tabular}

Baby could be brought out of the nursery at any time to be with mother. Window for mothers to see their babies in the nursery only open 8 (10) for certain hours of the day.

Baby could be brought out of the nursery at any time to be with mother but unable to see baby while in the nursery. 2 (3)

Baby only allowed out of the nursery during the day. No physical access to baby at night. However, mothers can see their babies through a 5 (6) window from outside of the nursery any time of the day or night. 
obtained help from family members. Of the 32 participants who hired a 'confinement lady', eight sought their assistance. From both the CC and Home groups, only 7 participants (4\%) sought help from lactation consultants.

\section{Discussion}

We found that exclusive breastfeeding rates at 1 month and 6 months appeared to be similar for mothers who went to $\mathrm{CCs}$ and those who stayed at home. This is contrary to current perceptions that CCs are a cause of early breastfeeding cessation due to numerous practices in CCs that hinder breastfeeding. One such practice which we found in our study was that CCs discouraged mothers from rooming-in with their babies. This was worrying as it causes significant separation of mother and infant and could disrupt the establishment as well as continuation of breastfeeding [15]. The practice of separating mothers from their babies at CCs was most likely due to the cultural emphasis on the need for postnatal mothers to rest during the confinement period $[4,7,8]$. A mother who is separated from her baby would not be able to detect the baby's feeding cues and thus, may miss breastfeeding opportunities. This turn may result in lower milk production [3].

It was interesting to note that more mothers were feeding expressed breast milk to their babies at CCs compared to home. While we did not further explore reasons for this, the most likely reason was that these mothers had the intention to breastfeed. However, due to limitations in access to their infants, both due to lack of rooming-in and in some cases restrictions in access to nurseries, they had chosen to do this in order to sustain breast milk feeding. We do not know if there was also a possibility of influences from commercial breast-pump industries [16] or if women in CCs could also be influencing each other to express milk rather than to directly breastfeed. There were also more primipara mothers in CCs, and a study in Hong Kong found that mothers with no previous breastfeeding experience were more likely to exclusively feed expressed milk [17].

While we do not have data for Malaysia, there are reports that expressed milk feeding is an increasing trend among ethnic Chinese mothers in neighbouring Singapore and Hong Kong [17-19]. This is a concern because there is a growing body of evidence that feeding expressed breast milk might be different from feeding at the breast. Studies have found that there is higher risk of asthma [20] and childhood obesity [21-23] with expressed breast milk feeding compared to direct breastfeeding. Studies have also found that only feeding expressed breast milk could result in early cessation of breastfeeding [17, 23-25]. Therefore, it is important for future studies to explore this trend to understand and address the factors that influence the choice to feed expressed milk rather than directly breastfeed.

Given all the above barriers to breastfeeding in CCs, it had been a surprise to find there were no difference in exclusive breastfeeding rates at 1 month and 6 months. A possible reason could be because all mothers included in this study had the intention to breastfeed and having such an intention is a recognized factor affecting breastfeeding duration [26]. We believe that this intention was the main factor why mothers in this study persevered with breastfeeding despite presence of some practices in CCs that hindered breastfeeding. Another reason for this finding was the perceived support that the mothers had from their CCs, even though there were gaps in the provision of support and a lack of understanding of what appropriate breastfeeding support actually entails. For example, despite restrictions in access to their babies and being discouraged from rooming-in or feeding at night (both of which are known barriers to breastfeeding), these mothers felt that their CC was supportive of breastfeeding. There is evidence that mothers who perceive that they are supported are more likely to successfully breastfeed [3].

Apart from the above, the breastfeeding experience in the two settings was similar. Mothers from both groups encountered people who hindered breastfeeding; some mothers in CCs had CC staff who discouraged breastfeeding while some of those who stayed at home had hired confinement ladies who discouraged breastfeeding. In both the groups, family members were also cited as a barrier to breastfeeding.

We found that there were more first-time mothers in the CC group. While there are no known published reports on this, the most likely reason is because CCs are a relatively new phenomena and are becoming increasingly available while the traditional confinement is less available due to the changing social structure, living arrangements and reduced availability of the traditional confinement lady. Younger mothers are more likely to use this facility while more experienced mothers might opt for what they had before, i.e. home care. In addition, first time mothers may also lack confidence to look after the baby themselves at home without a 'traditional confinement lady.' Another reason might be that multiparous mothers did not want to be separated from their other children. Future studies could be done to explore the validity of these explanations.

Our study is important because over the past decade there has been a rapid expansion of CC services not only in Penang and throughout Malaysia but also in other parts of the world including Singapore, Hong Kong and mainland China. Similar centres are also opening to cater for the traditional needs of the other Malaysian ethnic groups. Therefore, this study offers insight into 
the level of breastfeeding support that is currently being offered and the findings will be useful in determining how support can be offered to these centres and to mothers at home. We noted that only a few mothers sought help from lactation consultants or peer support groups. There is currently no formal recognition of lactation consultants in Malaysia and the number of certified consultants is very low. Peer support groups exist but again our data showed that these were not sought either by the CC or home participants. Efforts to link CCs and mothers at home with these groups are needed. This study also provides insight into the training needs of the CC staff.

A limitation of our study would be that our findings reflect only the views of mothers who at recruitment had the intention to breastfeed. These findings do not apply to mothers without an intention to breastfeed, and such studies are needed. In addition, this study is limited because we did not have data on which $\mathrm{CC}$ the mothers went to. However, while we believe that our sample of mothers reasonably represents the mothers using CCs in Penang, we do not believe that we have a reasonable representation of the CCs in Penang. It is likely not all CCs in Penang were represented in the data and it is possible that several of our participants could have been at any one of the CCs. Practices in each $\mathrm{CC}$ were different, with some more supportive of breastfeeding than others. Given that we recruited women who intended to breastfeed, we may have inadvertently selected CCs that were more likely to be supportive of breastfeeding. Therefore, our results might not be generalizable to all mothers attending all CCs in Penang. Another limitation of the study was the sample size. We based our sample size on the assumption that we could expect a $50 \%$ lower exclusive breastfeeding rate in the $\mathrm{CC}$ group. There were no available data to guide us in this estimate and we now believe this may have been an overestimation of the expected difference. Indeed, the sample size was barely adequate to meet this $50 \%$ assumption. Therefore, there is a possibility that there could be a difference between the two groups that we failed to demonstrate due to this overestimation.

\section{Conclusions}

We found that spending the traditional confinement period in CCs or at home did not appear to result in a difference in both exclusive breastfeeding and any breastfeeding rates at one and 6 months postpartum among Chinese mothers who intended to breastfeed. However, when describing their experience, we found definite gaps in how CCs were supporting breastfeeding. Ways to overcome this need to be explored. One such intervention might be to provide training to improve CC staff's ability to provide breastfeeding support. Such training would need to be tailored specifically to their needs and thus CC staff input into the design of an educational training package is recommended. Future studies could also be done on all mothers regardless of their intention to breastfeed.

\section{Abbreviations \\ BFHI: Baby Friendly Hospital Initiative; CC: confinement centre; vs: versus}

\section{Acknowledgements}

The authors acknowledge Ru Jian Jonathan Teoh (initial draft of the protocol); Drs Adele Tan, Hon Kit Cheang, Yee Chen Hwang, Giap Liang Dan, Jessica Tan, Kwai Meng Pong, Siti Khadijah Hamdan, Balkees Abdul Majeed (participant recruitment); Caryn Lim (initial data collection and data entry); Wei Wen Lee (data collection, phone interviews and data entry); Zcho Huey Lee (phone interviews and data entry); as well as all mothers and hospitals who participated in this study.

\section{Authors' contributions}

SCF, MLT, WCF AND JJH were major contributors in the design of the study and in writing the manuscript. WCF, FFR and SCF analysed and interpreted the data. FFR was the major contributor in writing the statistical sections of the manuscript. All authors read and approved the final manuscript.

\section{Authors' information}

SCF, MLT, WCF AND JJH are all paediatricians and advocates for breastfeeding.

\section{Funding}

RCSI \& UCD Malaysia Campus provided a research grant (PMC RC-17) but did not play any role in the design of the study, data collection, analysis and interpretation of data nor in the writing of the manuscript.

\section{Availability of data and materials}

The datasets used and/or analysed during the current study are available from the corresponding author on reasonable request.

\section{Ethics approval and consent to participate}

This study was registered with the National Medical Research Registry (NMRR-17-1174-36384 S1) and ethical approval by Joint Penang Independent Ethics Committee (JPEC 02-18-0026). All participants gave written informed consent.

\section{Consent for publication}

Not applicable.

\section{Competing interests}

The authors declare that they have no competing interests.

Received: 28 April 2020 Accepted: 10 December 2020

Published online: 06 January 2021

\section{References}

1. Stuebe A. The risk of not breastfeeding for mothers and infants. Rev Obstet Gynecol. 2009;2:222-31.

2. Moore ER, Bergman N, Anderson GC, Medley N. Early skin-to-skin contact for mothers and their healthy newborn infants. Cochrane Database Syst Rev. 2016;11:CD003519.

3. Jaafar $\mathrm{SH}, \mathrm{Ho} J$ J, Lee KS. Rooming-in for new mother and infant versus separate care for increasing the duration of breastfeeding. Cochrane Database Syst Rev. 2016;8:CD006641.

4. Dennis CL, Fung K, Grigoriadis S, Robinson GE, Romans S, Ross L. Traditional postpartum practices and rituals: a qualitative systematic review. Women Health. 2007;3(4):487-502.

5. Ding G, Tian $Y, Y u$ J, Vinturache A. Cultural postpartum practices of 'doing the month' in China. Perspect Public Health. 2018;138(3):147-9.

6. Poh B, Koon W, Yuen P, Norimah A. Postpartum dietary intakes and food taboos among Chinese women attending maternal and child health clinics and maternity hospital, Kuala Lumpur. Malays J Nutr. 2005;11:1-21. 
7. Raven JH, Chen Q, Tolhurst RJ, Garner P. Traditional beliefs and practices in the postpartum period in Fujian Province, China: a qualitative study. BMC Pregnancy Childbirth. 2007;7:8.

8. Fok D, Aris IM, Ho J, Lim SB, Chua MC, Pang WW, et al. A comparison of practices during the confinement period among Chinese, Malay, and Indian mothers in Singapore. Birth. 2016;43(3):247-54.

9. Su-Lyn B. New mothers paying big bucks to be 'confined'. Malay Mail 2013. https:/www.malaymail.com/news/malaysia/2013/07/07/new-motherspaying-big-bucks-to-be-confined/491853. Accessed 1 April 2020.

10. Teh SC, Chong SI, Tan HH, Ho J. Chinese mothers intention to breastfeed, actual achievement and early postnatal experience. Med J Malaysia. 2000; 55(3):347-51.

11. Tan KL. Factors associated with exclusive breastfeeding among infants under six months of age in peninsular Malaysia. Int Breastfeed J. 2011;6:2.

12. Institute for Public Health National Institutes of Health, Ministry of Health, Malaysia National Health and Morbidity Survey 2016: Maternal and child health. Vol I: Methodology and general findings 2016.

13. World Health Organization. Indicators for assessing infant and young child feeding practices (Part 1 Definitions), vol. 26. Washington, DC: World HealthOrganization; 2008.

14. StataCorp. Stata Statistical Software: Release 13. College Station: StataCorp LP; 2013.

15. Perez-Escamilla RSMS, Pollitt E, Dewey K. Effect of the maternity ward system on the lactation success of low-income urban Mexican women. Early Hum Dev. 1992;31:25-40.

16. Johns HM, Forster DA, Amir LH, McLachlan HL. Prevalence and outcomes of breast milk expressing in women with healthy term infants: a systematic review. BMC Pregnancy Childbirth. 2013;13:212.

17. Bai DL, Fong DY, Lok KY, Wong JY, Tarrant M. Practices, predictors and consequences of expressed breast-milk feeding in healthy full-term infants. Public Health Nutr. 2017;20(3):492-503.

18. Hornbeak DMDM, Sham WK, Li JL, Young TL, Wong TY, Chong YS, Saw SM. Emerging trends in breastfeeding practices in Singaporean Chinese women: findings from a population-based study. Ann Acad Med Singap. 2010;39:8894.

19. Jiang B, Hua J, Wang Y, Fu Y, Zhuang Z, Zhu L. Evaluation of the impact of breast milk expression in early postpartum period on breastfeeding duration: a prospective cohort study. BMC Pregnancy Childbirth. 2015;15: 268.

20. Klopp A, Vehling L, Becker AB, Subbarao P, Mandhane PJ, Turvey SE, et al. Modes of infant feeding and the risk of childhood asthma: a prospective birth cohort study. J Pediatr. 2017;190:192-9 e2.

21. Azad MB, Vehling L, Chan D, Klopp A, Nickel NC, McGavock JM, et al. Infant feeding and weight gain: separating breast milk from breastfeeding and formula from food. Pediatrics. 2018;142(4):e20181092

22. Li R, Fein SB, Grummer-Strawn LM. Do infants fed from bottles lack selfregulation of milk intake compared with directly breastfed infants? Pediatrics. 2010;125(6):e1386-93.

23. Pang WW, Bernard JY, Thavamani G, Chan YH, Fok D, Soh SE, et al. Direct vs. expressed breast milk feeding : relation to duration of breastfeeding. Nutrients. 2017;9(6):547.

24. Forster DA, Johns HM, McLachlan HL, Moorhead AM, McEgan KM, Amir LH. Feeding infants directly at the breast during the postpartum hospital stay is associated with increased breastfeeding at 6 months postpartum: a prospective cohort study. BMJ Open. 2015; 5(5):e007512-e.

25. Shealy KRSK, Labiner-Wolfe J, Fein SB, Grummer-Strawn LM. Characteristics of breastfeeding practices among US mothers. Pediatrics. 2008;122(Suppl): 50-5.

26. Schlickau JM. Prenatal breastfeeding education: an intervention for pregnant immigrant Hispanic women [dissertation]. University of Nebraska Medical Center; 2005 [cite 2020 April 21]. Available: http://hdl.handle.net/1 0755/18287.

\section{Publisher's Note}

Springer Nature remains neutral with regard to jurisdictional claims in published maps and institutional affiliations.

\section{Ready to submit your research? Choose BMC and benefit from:}

- fast, convenient online submission

- thorough peer review by experienced researchers in your field

- rapid publication on acceptance

- support for research data, including large and complex data types

- gold Open Access which fosters wider collaboration and increased citations

- maximum visibility for your research: over $100 \mathrm{M}$ website views per year

At BMC, research is always in progress.

Learn more biomedcentral.com/submissions 